\title{
Problemática ambiental e políticas públicas de meio ambiente no Distrito Federal
}

\author{
Fernando Negret Fernandez. \\ Pedro Pietrafesa
}

\begin{abstract}
Resumo
O estudo teve por objetivo analisar a problemática ambiental no Distrito Federal de Brasília e as políticas públicas que foram colocadas em execução para enfrentá-la. Estabeleceu-se, como ponto de partida, que a ocupação territorial e a urbanização desordenada constituem as causas principais da degradação do meio ambiente. Nessa perspectiva, foram considerados quatro aspectos para a análise e de atenção prioritária: a ocupação e o uso do solo, os recursos hídricos, os resíduos sólidos e a educação ambiental. $\mathrm{O}$ estudo apoiou-se em revisão bibliográfica e pesquisa documental, esta última abarcando as políticas públicas, a legislação e as iniciativas do governo do Distrito Federal. Os resultados mostraram que há uma bastante preocupante degradação dos recursos, porém, que também existe uma ampla legislação e normas pertinentes aos quatro aspectos acima referidos em particular.
\end{abstract}

Palavras-chave | Distrito Federal; políticas públicas; problemática ambiental; urbanização.

Classificação JEL | Q53 Q58 R11

\section{Environmental problems and environmental public policies in the Federal District}

\begin{abstract}
The study aimed at analysing the environmental problematic in the Federal District of Brasilia and the public policies that have been put in place to face it. It was established, as a starting point, that territorial occupation and disorderly urbanization are the main causes of environmental degradation. In this perspective, four aspects were considered for analysis and priority attention: the occupation and use of soil, water resources, solid waste and environmental education. The study was based on bibliographic review and documentary research, the latter covering public policies, legislation and initiatives of the Federal District government. The results showed that there is a rather worrying degradation of resources, but that there is also ample legislation and norms pertinent to the four aspects mentioned above in particular.
\end{abstract}


Keywords | Environmental problems; Federal District; public policies; urbanization.

JEL Classification | Q53 Q58 R11

\section{Problemática ambiental y políticas públicas de medio ambiente en el Distrito Federal}

\section{Resumen}

El estudio tuvo como objetivo analizar la problemática ambiental en el Distrito Federal de Brasilia y las políticas públicas que fueron puestas en marcha para afrontarla. Se estableció, como punto de partida, que la ocupación territorial y la urbanización desordenada son las principales causas de la degradación ambiental. En esta perspectiva, se consideraron cuatro aspectos para su análisis y atención prioritaria: la ocupación y el uso del suelo, los recursos hídricos, los residuos sólidos y la educación ambiental. El estudio se basó en la revisión bibliográfica y en la investigación documental, esta última abarcando las políticas públicas, la legislación e iniciativas del gobierno del Distrito Federal. Los resultados mostraron que existe una degradación bastante preocupante de los recursos, pero que también hay una amplia legislación y normas pertinentes a los cuatro aspectos mencionados en particular.

Palabras clave | Distrito Federal; políticas públicas; problemática ambiental; urbanización.

Clasificación JEL | Q53 Q58 R11

\section{Introdução}

O desenvolvimento deste estudo parte do entendimento de que a intensa migração e a consequente ocupação territorial e urbanização sem planejamento no território do Distrito Federal (DF) são a causa principal dos processos e fenômenos que mais degradam o meio ambiente nesta entidade federativa. Neste sentido, são identificados e selecionados os quatro processos ou condições socioambientais que mais degradam, para logo analisar políticas públicas, leis e iniciativas criadas pelo governo do DF para enfrentá-los e melhorar a qualidade ambiental e de vida da população.

O processo de ocupação territorial, iniciado desde a construção de Brasília de maneira acelerada e sem ordenamento regional e urbano, deveu-se em boa medida à grande disponibilidade de terras públicas e a facilidade da sua ocupação pelos numerosos migrantes que vinham para a nova capital federal a procura de emprego e de oportunidades de vida. Diversas ocupações das terras se realizaram mediante invasões, sem planejamento ou serviços e infraestrutura, e com desmatamento das áreas para assentar as moradias, ou seja, com graves problemas ambientais. $\mathrm{O}$ fato que evidencia a ocupação inicial com invasões de terra foi a criação de Ceilândia, em 1971, cujo nome incorpora CEI, referente à Campanha de Erradicação de 
Invasões, e lândia, um anglicanismo que pode significar terra, território e lugar (GOUVÊA, 1995). Efetivamente, Ceilândia recebeu população das principais invasões do DF, sendo transferidas as "do IAPI; das Vilas Tenório, Esperança, Bernardo Sayão e Colombo; dos morros do Querosene e do Urubu; e Curral das Éguas e Placa das Mercedes, invasões com mais de 15 mil barracos e mais de 80 mil moradores" (GDF, 2016, p. 1). Ceilândia foi implantada "em uma região de difícil acesso, com escassez de água e com abundância de Cerrado" (FERNANDES, 2002, p. 19.).

O governo do DF buscou inicialmente uma ocupação territorial mais ordenada mediante o planejamento das cidades-satélites e, mais recentemente, com a criação das 33 Regiões Administrativas e do estabelecimento do Zoneamento Ecológico Econômico (ZEE). Trata-se de um ordenamento territorial com uma visão mais socioambiental, levando em consideração potencialidades e vulnerabilidades do uso da terra, incluindo a proteção das áreas de mananciais e das bacias de abastecimento de água. No entanto, a urbanização e a metropolização de Brasília continua sendo o principal processo global responsável pela degradação do meio ambiente e da problemática socioambiental no território (GDF, 2019a).

Correlacionado com a acelerada urbanização, consideram-se como prioritários outros processos decorrentes, que foram selecionados para analisar neste estudo, bem como as políticas, programas e iniciativas do estado para confrontá-los. Esses processos e problemas ambientais são: a) o uso do solo e urbanização sem normas, controle e serviços básicos, incluindo os municípios de Goiás limítrofes ao DF e que hoje integram a Área Metropolitana de Brasília $\left(\mathrm{AMB}^{1}\right)$; b) a degradação dos recursos hídricos para o abastecimento de água a uma população crescente; c) o manejo dos resíduos sólidos; e, d) a educação ambiental e o grau de consciência social sobre a proteção do meio ambiente.

\section{Metodologia e aspectos conceituais}

$\mathrm{O}$ estudo foi desenvolvido, predominantemente, com base em pesquisa bibliográfica e documental, sobre os quatro aspectos socioambientais mais degradados e degradantes, sobre os quais existe maior número e diversidade de políticas públicas e ações institucionais. Inicialmente, faz-se aqui uma conceptualização e discussão da urbanização como processo determinante da problemática ambiental. Conceituam-se os quatro processos socioambientais decorrentes da urbanização, considerados mais importantes, selecionados para a análise e já mencionados: a) uso do solo e as formas de urbanização; b) recursos

\footnotetext{
${ }^{1}$ Municípios da AMB: Águas Lindas; Alexânia; Cidade Ocidental; Cocalzinho; Cristalina; Formosa; Luziânia; Novo Gama; Padre Bernardo; Planaltina de Goiás; Santo Antonio Descoberto; e Valparaíso de Goiás.
} 
hídricos e o problema do abastecimento de água; c) manejo dos resíduos sólidos; d) educação e consciência social sobre a problemática ambiental e a proteção do meio ambiente. Posteriormente, incluiu-se uma conceptualização de política pública e apresentam-se as estratégias do governo do Distrito Federal relativas aos quatro aspectos ou processos socioambientais de estudo relacionados acima.

\section{Conceito de urbanização}

Considerando a urbanização como o processo global determinante da problemática ambiental em Brasília, convém fazer uma breve conceptualização do mesmo com base em autores que a definiram a partir de suas próprias vivências no auge da expansão das cidades em América Latina, na década de 1970. Schteingart (1973, p. 11) considera a urbanização "um dos processos mais importantes que afetam o mundo atual e seu impacto é muito mais dramático nas sociedades em desenvolvimento". Para Quijano (1973, p. 19), "se trata de um fenómeno multidimensional que é uma das maiores expressões do processo geral de mudança de nossas sociedades". Castells (1976, p. 26) afirma que o "termo urbanização se refere ao mesmo tempo a constituição de formas espaciais específicas das sociedades humanas, caracterizadas pela significativa concentração das atividades e populações em um espaço restringido", além da existência de um particular sistema cultural: a cultura urbana. Os três autores - e vários mais - coincidem no entendimento da complexidade do processo de urbanização, que, além de significar a concentração da produção, do capital e da população nas cidades, na América Latina tem se caraterizado também como uma concentração da pobreza nas regiões periféricas urbanas em deficientes condições ambientais de vida.

O processo de urbanização, ocorrido com maior intensidade nas décadas 1960 e 1970 na América Latina e no Brasil, em particular, explica-se pela expansão do agronegócio com alto grau de capitalização e tecnologia sobre territórios com formas de produção familiar e atrasadas que foram deslocadas para as periferias das cidades em assentamentos não planejados, sem serviços, nem infraestrutura ou equipamentos sociais. No campo ocorre desmatamento e ocupação das áreas de preservação ambiental, enquanto nas cidades as periferias são ocupadas pelos migrantes em deficientes condições ambientais de vida (DELGADO, 2001).

Com relação à urbanização acelerada e as grandes cidades, Nakano e Pinto da Cunha (2012, p. 167) assinalam como o principal problema a prevalência dos modos desiguais e excludentes de produção das moradias e localizações urbanas, que levam os grupos sociais de menor renda a viver segregados em espaços urbanos precários e informais do ponto de vista fundiário. Para os autores, trata-se de modos socialmente injustos e ambientalmente insustentáveis.

Soares (2012) aborda a complexidade das metrópoles e considera entre outros aspectos, os novos empreendimentos imobiliários com diversas tipologias de habitação, centros de negócios e serviços, estabelecimentos produtivos e instalações 
para lazer, que constituem verdadeiras cidades completas. Nestes empreendimentos, a natureza dos lugares é atributo ambiental do empreendimento, com áreas naturais preservadas, amplos lotes, baixa densidade e jardins que valorizam o produto imobiliário e "alimentam os sonhos de consumo de moradia em espaços exclusivos” (SOARES, 2012, p. 109-110).

Soares (2012) faz uma reflexão sobre os conflitos decorrentes das formas de apropriação da natureza crescentemente privatizada, típica do processo de urbanização, ao tempo que destaca como o capitalismo contemporâneo assume nova postura ecológica com a qual busca resolver o dilema do crescimento econômico e preservação ambiental. Esta nova postura demanda uma atitude mais proativa da sociedade na regulação ambiental e controles ecológicos, os quais correspondem a um conjunto de políticas, arranjos institucionais e práticas regulatórias, buscando mais preservação e evitando a correção dos danos ambientais, muitos irreversíveis.

Nesta perspectiva, o Brasil e, particularmente, o Distrito Federal, têm avançado na formulação de políticas públicas de preservação ambiental e na criação de novas entidades para fazer gestão institucional. Entretanto, cabe ressaltar que muitos desses avanços institucionais e a formulação de políticas públicas, fiscalização e controle das florestas nacionais e dos recursos naturais estão sendo gravemente desestruturados. Em janeiro de 2021 foi publicado o relatório "Passando a Boiada" elaborado pelo Observatório do Clima, o qual mostra com evidencia a gravidade e dimensão do desmonte de todos os instrumentos de monitoramento e controle estruturados com base na constituição de 1988. O relatório afirma que o segundo ano desta administração foi marcado na área ambiental pelo aprofundamento de medidas adotadas a partir de 2019 para eliminar regulamentações e abdicar da gestão ambiental (WERNECK et al., 2021). Com relação ao enorme número de mudanças realizadas pelo governo na legislação ambiental, o relatório assinala que de janeiro a dezembro de 2020 houve 593 "canetadas" do governo federal relacionadas ao meio ambiente, sendo que 57 determinavam reformas institucionais, 32 eram revisões de regulamentos, 32 promoviam flexibilização, 19 desregulações e 10 eram revogações (WERNECK et al., 2021).

Com referência à relação urbanização e meio ambiente, Nunes, Serra e Steinke (2017, p. 723) afirmam que o processo de ocupação irregular se intensificou no Distrito Federal a partir do final da década de 1970 e que em razão da pressão imobiliária, da condescendência dos gestores públicos e da falta de fiscalização do governo para coibir estas ações, esses loteamentos foram se estabelecendo em áreas impróprias para urbanização, causando danos irreversíveis aos recursos hídricos. As afirmações destes autores mostram a complexidade da urbanização nas atuais metrópoles e em outras cidades brasileiras nas quais existem problemas ambientais decorrentes das deficiências de serviços básicos, com riscos de alagamentos ou desabamentos das moradias, bem como da problemática ambiental gerada por 
novas urbanizações de alto padrão, algumas ocasionando desmatamentos e ocupando áreas de preservação permanente.

Essa problemática ambiental recorrente em diversas cidades brasileiras tem gerado políticas públicas específicas, incluindo as do Distrito Federal, como se verá adiante. Entretanto, é necessário fazer uma conceptualização sobre Política Pública, logo enunciar aqui as políticas ambientais do DF e, finalmente, analisar seus resultados.

\section{Conceito de política pública}

Uma política pública é uma ação, conjunto de ações ou iniciativas propostas e executadas com participação de organismos do Estado, a qualquer nível, ou por uma comunidade de maneira conjunta ou associação de pessoas para determinado propósito de ordem coletiva. Em geral, as políticas públicas buscam atender direitos não reconhecidos às classes sociais mais pobres e minorias excluídas das sociedades. Uma política pública formulada no âmbito de uma sociedade democrática inclui um processo de consulta à população e às comunidades sobre suas necessidades com o fim de satisfazê-las, estabelecendo meios e instrumentos para a sua execução, monitoramento e fiscalização. Inclui também o processo de negociação e aprovação no âmbito do governo e o período de implementação na realidade social.

Com relação à determinação do carácter público de uma política, é conhecido que existem diversas opiniões. Particularmente, em torno do que determina o caráter público de uma política. Talvez exista o predomínio da ideia de que uma política é pública por ser originária do Estado, ou do "governo", como mais coloquialmente se usa o termo, entretanto uma comunidade local ou de um bairro, uma entidade privada, política ou religiosa ou até uma pessoa física, podem propor, formular e executar uma política pública. Uma comunidade de um bairro, por exemplo, pode propor uma política de manejo do lixo ou de arborização das ruas. Alguma entidade privada ou religiosa, por exemplo, pode sugerir uma política de ajuda aos mais pobres ou construir um centro comunitário em um bairro para ministrar cursos de capacitação; ou um líder local pode propor atividades esportivas ou artísticas para crianças e adolescentes.

Secchi (2011, p. 14) considera que o carácter público de uma política é determinado pela atuação direta do Estado. Para o autor, é a supremacia e a hierarquia do Estado na elaboração e execução das leis o que determina o carácter público das políticas. Além disso, o Estado pode garantir o seu cumprimento porque tem a capacidade de executar as suas propostas de políticas. Secchi (2011), considera que o foco da política pública é o problema público. Rua e Romanini (2013, p. 8), na mesma perspectiva, entendem a política pública como ações geradas sob a autoridade soberana do Estado. Segundo Rua e Romanini (2013), política pública é um conjunto de procedimentos formais e informais que expressam relações de poder e que se destinam à resolução pacífica dos conflitos no que diz respeito aos interesses públicos. Entretanto, não necessariamente para a resolução de conflitos, como 
afirmam Rua e Romanini (2013), pois podem ser políticas recreativas, culturais e esportivas. Também podem ser políticas orientadas à melhoria das condições de vida da população nacional, regional ou local.

Souza (2002) destaca os conceitos de política pública de vários autores. Lynn (1980), define política pública como um conjunto específico de ações de governo orientadas a produzir determinados efeitos. Peters (1986), considera que política pública é a soma das atividades dos governos, atuando diretamente ou por delegação, que influenciam a vida dos cidadãos. Dye (1984) sintetiza a política pública como "o que o governo escolhe fazer ou não fazer" (SOUZA, 2002, p. 4).

Outras definições enfatizam o papel da política pública na solução de problemas. Entretanto, autores críticos dessas definições consideram que estas superestimam aspectos racionais e procedimentais das políticas públicas que implicam o debate em torno de ideias e interesses. Além disso, essas definições deixam de lado aspectos conflituosos e os limites que cercam as decisões dos governos (SOUZA, 2002).

A partir destas definições pode-se concluir que política pública é uma formulação de propósitos e ações para atender direitos fundamentais da população, tanto por iniciativa do Estado como de outras instâncias coletivas de iniciativa popular, empresarial ou individuais. Com relação aos quatro problemas ambientais selecionados para análise, apresenta-se a seguir seus conceitos, as políticas públicas respectivas no Distrito Federal e, posteriormente, os resultados obtidos com a implementação destas políticas.

\section{Conceito de uso do solo e política pública do $\mathrm{DF}$}

A Ocupação e Uso do Solo como norma é uma lei que estabelece instrumentos de ordenamento territorial, os quais "definem a distribuição espacial das atividades, a densificação e a configuração da paisagem urbana no que se refere à edificação e ao parcelamento do solo" (PORTO ALEGRE, 2007).

A Lei N. 10.257 de 2001, que corresponde ao Estatuto da Cidade, estabelece as diretrizes gerais da Política Urbana do Brasil. Particularmente, no art. $2^{\circ}$ ela orienta o ordenamento e controle do uso do solo, evitando a utilização inadequada dos imóveis; usos incompatíveis próximos; parcelamento; edificação inadequada em relação à infraestrutura instalada; estabelecimento de atividades geradoras de tráfico; e degradação de zonas urbanas. (BRASIL, 2001).

Neste sentido, o uso do solo é regulado por normas que estabelecem diretrizes e critérios para a ocupação e construção de zonas de uso urbanas e rurais, mas existem dificuldades para realizar monitoramento e fiscalização. No caso do Distrito Federal, seu Zoneamento Ecológico Econômico (ZEE-DF) é definido como um instrumento estratégico de planejamento e gestão territorial, com diretrizes e critérios que orientam as políticas públicas de desenvolvimento socioeconómico e de melhoria das condições de vida. O ZEE se considera "um zoneamento de riscos 
tanto ecológicos quanto socioeconômicos a ser obrigatoriamente considerado para o estabelecimento de zonas de usos" (GDF, 2019a).

\section{Conceito de resíduos sólidos e política pública do DF}

A Política Nacional de Resíduos Sólidos, instituída pela Lei N. 12.305, de 2010, conceitua como resíduos sólidos qualquer material, substância, objeto ou bem descartável, nos estados sólido e semissólido. Eles devem ser descartados adequadamente (BRASIL, 2010). No art. 13 desta lei e para seus efeitos, classifica os resíduos sólidos quanto a: a) origem, nos quais inclui os domésticos e todos os oriundos de atividades urbanas como o comércio, serviços, saúde e saneamento básico, resíduos industriais, da construção civil e de transporte, do meio rural, incluindo os agrossilvopastoris e de mineração; e b) periculosidade, nos quais se incluem aqueles inflamáveis, corrosivos, reativos, tóxicos, patogénicos, cancerígenos e outros com riscos à saúde pública e a qualidade ambiental (BRASIL, 2010).

O DF estabeleceu a Lei 5.418 de 2014, que dispõe sobre a Política Distrital de Resíduos Sólidos e dá outras providências. Segundo o artigo $1^{\circ}$, parágrafo único, "as disposições desta Lei são aplicadas em consonância com a Lei Federal N. 12.305, de 2010 - Política Nacional de Resíduos Sólidos” e revoga as disposições em contrário (GDF, 2014).

\section{Conceito de recursos hídricos e política pública do DF}

A Política Nacional de Recursos Hídricos foi instituída pela Lei N. 9.433 de 1997, também conhecida como Lei das Águas, a qual cria o Sistema Nacional de Gerenciamento de Recursos Hídricos. A lei se baseia em seis fundamentos, dos quais dois deixam claro o conceito de água: é um bem de domínio público e um recurso natural limitado, dotado de valor econômico (BRASIL, 1997).

O DF estabeleceu a Lei N. 2.725 de 2001 que institui a política de recursos hídricos e cria o sistema de gerenciamento de recursos hídricos e dá outras providencias. Desta forma, a lei distrital está concebida no contexto da Lei Nacional N. 9.433 (BRASIL, 2001).

\section{Conceito de educação ambiental e a política pública do DF}

A Lei N. 9.795 de 1999 estabelece a Política Nacional de Educação Ambiental. Dois conceitos sobre esta matéria propostos na lei são os seguintes: no $\operatorname{artigo} 1^{\circ}$, a educação ambiental é definida como "processos por meio dos quais o indivíduo e a coletividade constroem valores sociais, conhecimentos, atitudes e competências orientadas para a conservação do meio ambiente" como bem público (BRASIL, 1999). No seu artigo $2^{\circ}$, estabelece que a educação ambiental é um componente 
essencial e permanente da educação nacional que deve estar presente em todos os níveis e modalidades do processo educativo formal e não formal.

Os dois conceitos são relevantes e claros, mencionando que a educação ambiental são valores sociais, conhecimentos, atitudes e competências construídos pelo indivíduo e pela coletividade para conservar o meio ambiente como bem comum do povo, assinalando, com isso, que o meio ambiente é um direito de todos, mas também um dever de todos protegê-lo. Igualmente é relevante que se estabeleça que a educação ambiental deve estar presente em todos os níveis e modalidades do processo educativo, o qual não ocorre como é necessário no momento atual de graves problemas e riscos ambientais.

A Lei N. 3.833 de 2006, dispõe sobre a educação ambiental e institui a Política de Educação Ambiental do Distrito Federal, criando o Programa de Educação Ambiental do Distrito Federal. É complementar à Lei Federal N. 9.795/ 99 no âmbito do Distrito Federal, e dá outras providências (BRASIL, 2006).

\section{Resultados}

Neste item são apresentados os quatro aspectos e problemas ambientais no Distrito Federal, quais sejam: uso do solo, degradação dos recursos hídricos, manejo do lixo e educação ambiental. Sobre cada um desses quatro aspectos são expostas, adiante, as políticas públicas formuladas e as ações realizadas no DF. Entretanto, é conveniente assinalar que o DF conta com diversas leis e decretos que dispõem sobre políticas públicas ambientais relativas a diversos aspectos do meio ambiente no seu território, não obstante, é a Lei N. 41 de 1989, a mais geral e de alcance maior, que dispõe expressamente sobre a Política Ambiental do Distrito Federal (PADF) e dá outras providências. Esta lei distrital foi estabelecida oito anos após a edição da Lei 6.938 de 1981, que dispõe sobre a Política Nacional do Meio Ambiente (PNMA) seus fins e mecanismos de formulação e aplicação, além de dar outras providências. Nesse sentido, é relevante analisar inicialmente os enfoques das duas políticas.

\section{Enfoques da Política Nacional de Meio Ambiente e da Política Distrital do Meio Ambiente}

É relevante destacar as diferenças na formulação das duas políticas, particularmente quanto aos objetivos e resultados que se pretendem obter com a implementação destas duas iniciativas.

A PNMA, no art. $2^{\circ}$ estabelece como objetivo geral "a preservação, melhoria e recuperação da qualidade ambiental propícia à vida, visando assegurar, no país, condições ao desenvolvimento socioeconômico, aos interesses da segurança 
nacional e à proteção da dignidade da vida humana". Como objetivos específicos, de forma resumida, tem-se o seguintes: (i) desenvolvimento econômico social sustentável; (ii) estabelecimento de normas e padrões de qualidade ambiental para o manejo de recursos ambientais e em áreas prioritárias; (iii) desenvolvimento de pesquisas e tecnologias nacionais e sua divulgação para o uso racional de recursos ambientais; (iv) formação de consciência pública sobre a preservação e restauração do meio ambiente; (v) imposição ao poluidor e ao predador a obrigação de recuperar e/ou indenizar os danos causados e ao usuário a contribuição pela utilização dos recursos ambientais com fins econômicos (BRASIL, 1981).

Como pode ser verificado, esses objetivos são subsidiários ou instrumentais do desenvolvimento sustentável nacional, e estão orientados ao manejo territorial do meio ambiente mediante a formulação de normas para manter a qualidade ambiental e manejar os recursos ambientais. Igualmente desenvolver pesquisas e obter tecnologias apropriadas à realidade nacional para o manejo dos recursos, as quais devem ser divulgadas para a formação de uma consciência pública sobre manejo ambiental. Além disso, institucionalizar a punição ao poluidor e ao predador pelos danos causados, e ao usuário a obrigação de contribuir pela utilização dos recursos ambientais.

Por sua parte, a PADF (GDF, 1989), tem como objetivos: o estímulo cultural à adoção de hábitos, costumes, posturas e práticas sociais não prejudiciais ao meio ambiente; adequação das atividades socioeconômicas rurais e urbanas às imposições do meio ambiente onde se inserem; preservação, conservação e manejo racional dos recursos renováveis e não renováveis; utilização adequada do espaço territorial e dos recursos hídricos destinados para fins urbanos e rurais, definindo normas de uso e ocupação, de construção de projetos, de conservação e preservação de áreas, e tratamento e disposição final de resíduos e efluentes; provimento de infraestrutura sanitária e condições de salubridade urbana; substituição gradativa, seletiva e priorizada de processos de produção agrícola e industrial perigosos.

Os objetivos da PADF começam com a correta iniciativa de privilegiar a cultura para adotar novos hábitos, atitudes e práticas não prejudiciais ao meio ambiente e isso a diferencia da PNMA. Também inclui um conjunto de ações em defesa e preservação do meio ambiente com atividades socioeconômicas de menor impacto a todos os níveis territoriais, mediante a preservação e conservação dos recursos naturais e produção de bens e serviços evitando o impacto ambiental e efeitos contra a saúde pública. Define normas para a ocupação e o manejo adequado do território e dos recursos hídricos, além da preservação e conservação de áreas e o tratamento e disposição de resíduos. Finalmente, mediante a instalação de saneamento básico e melhoria dos processos agrícolas e industriais poluentes. Esses coincidem com os quatro aspectos de análise, uso e ocupação de território, os recursos hídricos, o manejo dos resíduos sólidos e a educação e consciência ambiental (GDF, 1989). 
Cabe assinalar que a política do Distrito Federal incorpora alguns aspectos específicos da realidade distrital. Em primeira instância, a PADF insere e destaca como primeiro objetivo o estímulo cultural à adoção de consciência e a educação ambiental no Distrito Federal. A sua relevância está em que já é uma premissa de consenso que a educação ambiental é um instrumento básico para a busca de um desenvolvimento com maior sustentabilidade. É ponto de partida para enfrentar os grandes desafios de ordem ambiental com os quais se defronta o mundo hoje. Neste sentido, vale lembrar "o debate sobre a substituição da educação ambiental pelo de educação para o desenvolvimento sustentável, para um futuro sustentável ou para a sustentabilidade" (GONZÁLES, 2000, p. 29).

Outro aspecto prioritário da política distrital de meio ambiente é o manejo adequado dos recursos hídricos, pois já existe uma ameaça objetiva de abastecimento de água, a qual teve a mais drástica manifestação com o racionamento de 15 meses entre 2016 e 2017. Nesse período, o volume do reservatório do Descoberto chegou a 9\% e o do Santa Maria a 22\%. Esses dois reservatórios são responsáveis por $87 \%$ do abastecimento de água de Brasília (ADASA, 2017). Esta situação preocupante do serviço de água do DF gerou políticas e ações ambientais no território, como a busca de novas fontes de captação de água que incluiu no Lago Paranoá, interligações entre os sistemas de abastecimento atual, maior fiscalização das ligações de água não autorizadas, controle das perdas de água nas redes de distribuição, manejo racional do recurso e incremento da educação ambiental.

\section{Principais problemas ambientais no Distrito Federal decorrentes da urbanização, políticas públicas para enfrentá-los e ações realizadas}

\section{Problemática de uso do solo, política pública e ações realizadas no DF}

Como é conhecido, a grande dimensão das terras públicas no território do DF facilitou a ocupação e uso do solo com assentamentos informais e não planejados de operários que chegavam de forma crescente a partir do início das obras de Brasília, em 1956. Neste sentido, Paviani (1985, p. 61) afirma que a fase da construção de nova capital "ficou marcada pelo frenesi das obras e consequente afluxo de operários da construção civil". Sendo que "o maior contingente populacional habita a periferia do Plano Piloto, ou seja, 3/4 da população encontrase nas cidades satélites, muito carentes de infraestrutura" (PAVIANI, 1985, p. 63). Desse modo, desde a construção da capital já existiam deficientes serviços básicos e problemas ambientais na sua periferia, que ainda perduram em alguns assentamentos informais. Segundo a Secretaria de Estado de Gestão do Território e Habitação, em 2015 existiam 392 parcelamentos de solo irregulares no DF com uma população estimada de 440.637 habitantes e 127.832 unidades habitacionais (CODEPLAN, 2016, p. 26). 
O DF aprovou a Lei Complementar N. 948 em janeiro de 2019, denominada Lei de Uso e Ocupação do Solo do Distrito Federal (Luos). Essa lei estabelece os critérios e os parâmetros de uso e ocupação do solo para lotes e projeções localizados na Macrozona Urbana do Distrito Federal. A lei também determina critérios e normas para os parcelamentos urbanos específicos. Dentre os objetivos da Luos, diretamente relacionados com o uso do solo e os aspectos ambientais, destacam-se os seguintes: aumentar a diversidade de usos e atividades para reduzir os deslocamentos; propiciar o ordenamento do território proposto no Plano Diretor de Ordenamento Territorial do Distrito Federal (PDOT) pertinente a esta Lei Complementar; promover a manutenção de áreas com vegetação e para arborização e definir parâmetros de uso e ocupação do solo de novos parcelamentos com a Luos (GDF, 2019c).

Dos objetivos expostos, o primeiro deles - aumentar a diversidade de usos e atividades para redução de deslocamentos - tem ocasionado uma grande controvérsia entre empresários, profissionais e moradores das áreas residenciais mais exclusivas do DF. Com base nesse objetivo foi aprovada a instalação de escritórios de advocacia nas áreas residenciais do Lago Sul e Norte e o Park Way. Esta aprovação contraria a manifestação e desejo dos moradores dessas áreas nas audiências públicas, porque consideram que essa mudança de uso do solo vai perturbar a tranquilidade nas suas residências e o tráfego veicular degradará a qualidade ambiental de vida e o caráter residencial destas zonas.

Em 25 de setembro de 2020 a Secretaria de Desenvolvimento Urbano de Habitação (Seduh) apresentou uma minuta do projeto de lei complementar que propõe alterações a Lei N. 948, incluindo a incorporação de novos projetos urbanos e de regularização fundiária registrados em cartório. Em novembro, o Conselho de Planejamento Territorial e Urbano do DF (Conplan) aprovou, por unanimidade, a minuta do projeto de lei complementar de revisão da Luos (GDF, 2020a). Desta forma, percebe-se que a Lei de Uso do Solo do DF continua sendo ajustada e no início de 2021 não se tinha conhecimento do avanço na aplicação das alterações propostas somente dois meses antes.

O Distrito Federal conta também com a Lei N. 5.803/2017, que institui a Política de Regularização de Terras Públicas Rurais pertencentes ao Distrito Federal ou a Agência de Desenvolvimento do Distrito Federal (Terracap) e dá outras providências(GDF, 2017a). Esta lei foi alterada pele recente Lei N. 6.740, de 03 de dezembro de 2020, mas mantém como objetivos promover a regularização de ocupações em terras públicas rurais e ordenar a ocupação e a exploração do território rural do Distrito Federal. No parágrafo $1^{\circ}$ se estabelece que as terras rurais que venham a ser incorporadas ao patrimônio do Distrito Federal ou da Terracap podem ser regularizadas nos termos desta lei (GDF, 2020b).

A regularização da terra no DF é uma necessidade primordial, pois reconhece a desordem da ocupação da terra e tem por objetivo "ordenar a ocupação e a 
exploração do território rural do DF". É essa ocupação desordenada a que ocasionou o grave impacto ambiental, particularmente nos recursos hídricos, sendo prioritário a recuperação dos danos e impactos ocasionados sobre os recursos naturais.

Cabe mencionar que a Lei N. 6.269, de 29 de janeiro de 2019, que institui o Zoneamento Ecológico-Econômico do Distrito Federal. $\mathrm{O}$ art. $1^{\mathrm{o}}$ desta lei institui o ZEE-DF como instrumento estratégico de planejamento e gestão territorial, cujas diretrizes e critérios passam a orientar as políticas públicas distritais voltadas ao desenvolvimento socioeconômico sustentável e à melhoria da qualidade de vida da população.

O ZEE-DF tem por objetivo geral a promoção da sustentabilidade no Distrito Federal nas dimensões social, econômica, ambiental e político-institucional, compatibilizando o desenvolvimento socioeconômico inclusivo com os riscos ecológicos e os serviços ecossistêmicos (GDF, 2019b). Desta forma, o ZEE pode se tornar um instrumento relevante para o ordenamento do uso do solo, entretanto, cabe assinalar que a sua implantação e a obtenção dos propósitos estabelecidos acima com relação à sustentabilidade constituem um desafio praticamente inalcançável. Em termos sociais, a sustentabilidade implica que toda a população tenha condições de vida sadias e resolvidas às suas necessidades básicas prioritárias. Entretanto, as desigualdades sociais são enormes. As favelas Pôr do Sol e Sol Nascente exemplificam este ponto, uma vez que possuem 91.066 habitantes, segundo projeção para 2020, e estão entre as maiores do Brasil (CODEPLAN, 2019). Em termos de sustentabilidade econômica, o DF ainda não conseguiu desenvolver uma estrutura produtiva não contaminante e intensiva em força de trabalho para resolver o problema de desemprego na periferia. Em termos ambientais, o impacto da urbanização já ocasionado sobre os recursos é grave, particularmente sobre a água, a vegetação, o solo e a biodiversidade. A sustentabilidade ambiental é a de maior dificuldade para ser restaurada. O objetivo de atingir uma sustentabilidade político-institucional pode ser interpretado como a possibilidade de que as instituições se mantenham permanentemente ativas em defesa de meio ambiente. Porém, essa perspectiva não tem acontecido, e como se viu, segundo o relatório "Passando a Manada", as instituições e normas de monitoramento e fiscalização têm sido desmontadas. Os recursos ambientais estão ameaçados agora mais do que antes.

\section{Problemática dos recursos hídricos, política distrital e açôes realizadas no $D F$}

O processo de urbanização sem planejamento, como já foi assinalado, levou à ocupação de nascentes de água, áreas de recarga, matas ciliares e margens dos rios, todas estas Áreas de Preservação Permanente (APP), que são fundamentais para a proteção dos recursos hídricos. Esse tem sido um dos impactos ambientais mais 
graves da urbanização desordenada e sem controle no Distrito Federal, o qual levou, em boa medida, ao drástico racionamento de água entre 2016 e 2017 no território do DF.

Desde 2001 o Distrito Federal conta com a Lei N. 2.725, que institui a política de recursos hídricos e cria o sistema de gerenciamento dos mesmos. Os objetivos desta lei são: assegurar a disponibilidade de água na qualidade e quantidade necessárias aos diferentes usos; promover a sua utilização racional; desenvolver iniciativas para a prevenção e atuação contra eventos de origem natural ou decorrentes de sua utilização inadequada e aumentar a sua disponibilidade (BRASIL, 2001). Esses objetivos são fundamentais e mantêm a sua vigência e validade. A falta de ações rigorosas para a obtenção dos mesmos levou ao racionamento de água durante 15 meses entre 2016 e 2017, período em que medidas emergenciais foram necessárias para enfrentar o desabastecimento.

Na capital federal foi criada a Conferência Distrital do Meio Ambiente pelo Decreto 12.960, de 1990, que regulamenta a Lei N. 41 de 1989 sobre a Política Ambiental do Distrito Federal. Em 2017, esta conferência teve como "foco qualificar, validar e colher a visão da sociedade sobre o que tem sido feito no ambiente e no cuidado com a água no território do Distrito Federal" (GDF, 2001, p. 1).

Nessa perspectiva, o texto base da Conferência do Meio Ambiente 2017: Cuidando das Águas, afirma que "a qualidade da água é um critério importante para a política pública de atendimento à saúde, da produção de alimentos e do meio ambiente" (GDF, 2017b, p. 5). Neste sentido, recomenda-se compatibilizar as diretrizes entre essas áreas de gestão. Segundo o texto base da conferência supracitada, ainda não existem estímulos econômicos suficientes para o cuidado com a água e com os serviços ambientais. Essas considerações são importantes para a formulação de uma política adequada sobre a água, no sentido de que se menciona o papel crucial deste recurso para a qualidade de outros serviços fundamentais das condições de vida da população, além de serem necessários recursos adicionais para contar com uma qualidade ambiental aceitável.

O documento menciona que o crescimento urbano desordenado ocupando áreas que prestam serviços ambientais como matas ciliares, áreas de recarga de aquíferos e nascentes, representam um grave impacto sobre a preservação da água no território distrital e que uma política pública deve atuar garantindo a permanência dessas áreas e do manejo integral das águas superficiais, dos aquíferos subterrâneos, das águas da chuva e das residuais residenciais, agropecuárias e industriais. Ou seja, trata-se de propor uma política para cuidar da água considerando a bacia como um todo, abrindo o diálogo, a participação e a cooperação da sociedade civil, empresas, academia e governos.

Devido à escassez de chuva, ao incremento do consumo de água pela expansão demográfica e à urbanização, à alta captação do recurso para irrigação, às captações não autorizadas e à ocupação de áreas de preservação ambiental reduziu 
drasticamente o volume de água nos reservatórios. Perante esta situação, a Agência Reguladora de Águas, Energia e Saneamento Básico do DF (Adasa), mediante a resolução 20 de 2016, declarou o estado de restrição dos recursos hídricos e estabeleceu o racionamento do serviço de água nas localidades atendidas pelos reservatórios do Descoberto e Santa Maria (ADASA, 2016).

Em março de 2017 o governo do Distrito Federal apresentou o Plano Integrado de Enfrentamento à Crise Hídrica, o qual incluía 44 ações com cooperação de 19 órgãos, divididas em quatro eixos de atuação: "Fiscalização, Infraestrutura, Educação e Regulação". Estas ações são complementares de outras medidas antes adotadas, como o racionamento de água, a redução de seu volume para irrigação na Bacia do Rio Descoberto, recuperação de canais, o investimento em novas fontes de captação, além de campanhas de educação e conscientização sobre o seu uso racional (AGÊNCIA BRASÍLIA, 2017).

O racionamento de água no Distrito Federal levou à implementação de várias políticas e ações do governo distrital e da Companhia de Saneamento Ambiental do Distrito Federal (Caesb), dentre as quais se destacam: melhorias e substituições nas redes de distribuição; novas fontes de captação de água e melhorias e reativação de antigas; interligações entre os sistemas de Descoberto e Santa Maria; recuperação da estação de tratamento do Rio Descoberto e fiscalização para evitar as ligações clandestinas e programas de educação ambiental. Algumas destas ações foram realizadas, outras estão ocorrendo. Como pode ser verificado na Figura 1, após as medidas de gestão hídrica anunciadas pelo governo distrital em 2017 houve uma redução de 9,55\% no consumo de água em relação ao ano de 2016, nos dois anos seguintes o consumo voltou a crescer. Contudo, no total, entre 2016 e 2019 a diminuição acumulada no consumo de água foi de 1,92\% (ADASA, 2021).

\section{Figura 1 - Consumo total anual de água no Distrito Federal, 2016-2019}

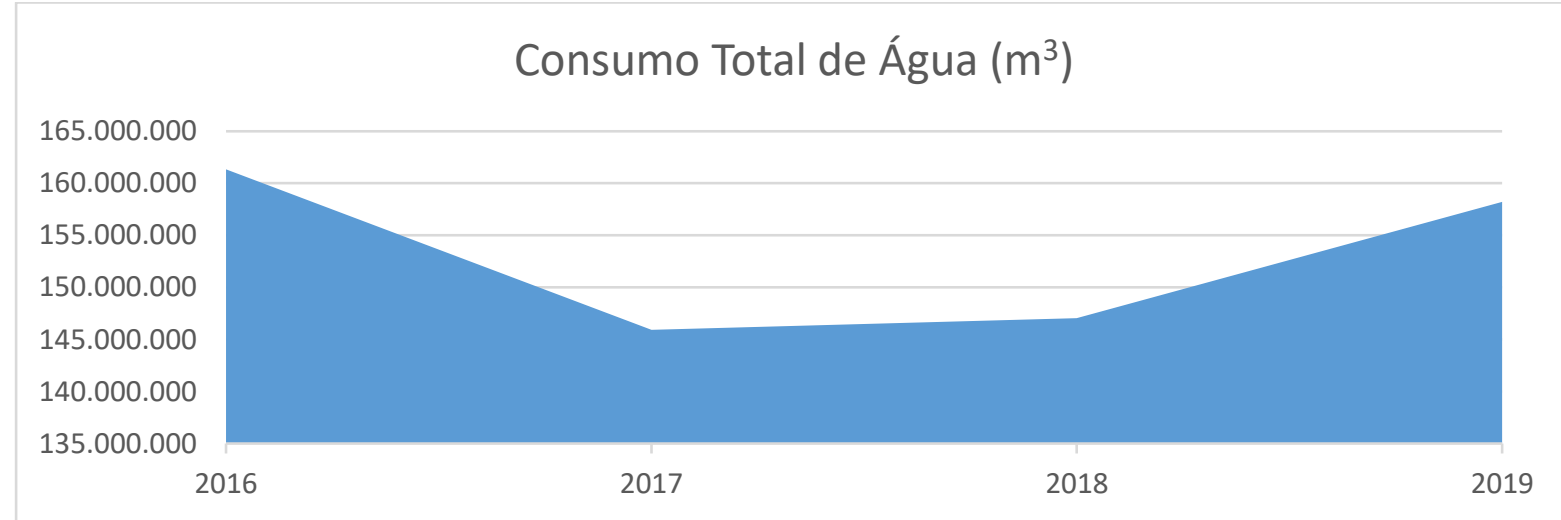

Fonte: Codeplan, 2021. 
Somada à implementação do plano governamental após a crise hídrica, uma melhoria no regime de chuva com altos índices de pluviosidade tem mantido os reservatórios com níveis completos do volume útil, sendo que em 19 de março de 2021, o do Descoberto estava em 100\% e do Santa Maria de 99,9\% (ADASA, 2021).

\section{Problemática dos resíduos sólidos, política distrital e ações realizadas no DF}

O manejo dos resíduos sólidos tem sido um dos problemas ambientais mais complexos em algumas das regiões administrativas do Distrito Federal, particularmente em assentamentos urbanos informais, nos quais existem dificuldades para o acesso e circulação de caminhões coletores do lixo devido às estreitas ruas nesses bairros. Entretanto, o problema fundamental em quase todas as regiões administrativas do Distrito Federal é a falta de educação e consciência ambiental da população, que continua depositando seus resíduos nas ruas e nos lotes vazios, ocasionando contaminação do ambiente e facilitando a reprodução de vetores de doenças, particularmente da dengue.

O DF conta com a Lei N. 5.418 de 2014, que dispõe sobre a Política Distrital de Resíduos Sólidos e dá outras providências. Segundo o artigo $1^{\circ}$, Parágrafo Único, "as disposições desta Lei são aplicadas em consonância com a Lei Federal N. 12.305, de 2 de agosto de 2010 - Política Nacional de Resíduos Sólidos” (BRASIL, 2010). Apesar do grande número de itens e aspectos incorporados na lei de resíduos sólidos, não é mencionada a necessidade iniludível de campanhas educativas com a população para o tratamento adequado do lixo e sua disposição final, bem como a instituição de mecanismos coercitivos para que as comunidades não continuem depositando ou lançando os resíduos em lugares impróprios.

Em 2018, como resultado e produto da política, foi publicado o Plano Distrital de Gestão Integrada de Resíduos Sólidos (PDGIRS), cujos objetivos são: 1) atender a legislação vigente para proporcionar os serviços de limpeza urbana e manejo dos resíduos sólidos com eficiência, qualidade e metas definidas com participação coletiva; e 2) desenvolver a gestão integrada dos resíduos sólidos no DF mediante um processo ordenado e eficiente de coleta, reciclagem, tratamento e disposição final.

É importante mencionar que no processo de elaboração PDGIRS foram executadas várias ações buscando envolver a população como previsto no Plano de Mobilização Social, sendo realizadas entrevistas e oficinas com entidades de classe, organizações não governamentais (ONGs), associações, sindicatos e órgãos públicos, sobre temas de manejo dos resíduos sólidos.

A partir da aprovação do PDGIRS foram realizadas várias ações sobre manejo de resíduos sólidos, dentre as que se podem mencionar o Instituto Ecozinha, uma organização civil de direito privado, que reúne 86 restaurantes associados, a qual tem produzido quase 1500 toneladas de resíduo orgânico compostado. Há também 
outra iniciativa da sociedade civil, o Projeto Compostar, criado em 2017, que amplia a economia circular, recolhendo restos alimentares em casas e apartamentos e em estabelecimentos diversos como restaurantes, bares, casas de festas e uma escola para produzir adubos orgânicos.

Em dezembro de 2019, a Câmara Legislativa do Distrito Federal aprovou o Projeto de Lei N. 355/2019, que determina a destinação de resíduos sólidos orgânicos no DF ambientalmente adequada, devendo ser, portanto, submetidos a processos de reciclagem e compostagem. O projeto de lei prevê ainda estímulo de iniciativas comunitárias, de associações e cooperativas na gestão desses resíduos. O resultado imediato desta lei é que o governo do Distrito Federal não poderá mais incinerar ou enviar resíduos sólidos orgânicos para os aterros sanitários (CÂMARA DOS DEPUTADOS, 2019).

De acordo com PDGIRS, a estratégia do governo distrital é aumentar a capacidade de compostagem, que é realizada por meio das duas Unidades de Tratamento Mecânico Biológico (UTMBs), e da coleta seletiva de resíduos orgânicos. O indicador que observa a eficiência da produção per capita de composto orgânico sugere que, no Distrito Federal, a sua quantidade por habitante ainda é "mediana", sendo a meta passar para "boa" a partir de 2022 (GDF, 2018).

\section{Problemática da educação ambiental, política distrital e ações realizadas no $D F$}

A educação ambiental é um fator determinante para a melhoria das condições de vida em diversas regiões administrativas e assentamentos do Distrito Federal. Os problemas relacionados com a desordenada ocupação e uso do solo, com a degradação das áreas de preservação permanente que protegem a sustentabilidade dos recursos hídricos, o uso inadequado do serviço de água e a falta de manejo dos resíduos sólidos, especialmente domésticos em alguns assentamentos, são resultado da falta de educação e de consciência social ambiental da população. Neste sentido, a problemática é analisada com relação às políticas públicas do governo do DF para a educação ambiental formal nos programas acadêmicos das escolas, e informal para a população em geral mediante campanhas educativas do poder público.

Desde 1996 foi estabelecida a Lei N. 1.146 que dispõe sobre a introdução da educação ambiental como conteúdo das matérias, atividades e disciplinas curriculares do $1^{\circ}$ e $2^{\circ}$ graus dos estabelecimentos de ensino do Distrito Federal. Posteriormente foi aprovada em 2006 a Lei Distrital N. 3.833, que dispõe sobre a educação ambiental, institui a Política de Educação Ambiental do Distrito Federal, cria o Programa de Educação Ambiental do Distrito Federal, complementa a Lei Federal N. 9.759/1999 no âmbito do Distrito Federal, e dá outras providências. Finalmente, é aprovado o Decreto Distrital N. 31.129 de 2009 que regulamenta a Lei Distrital N. 3.833. Esta lei inclui o seguinte conceito de educação ambiental e as instituições escolares que a devem ministrar: "art. 10. Entende-se por educação 
ambiental, no ensino formal, a desenvolvida no âmbito dos currículos e atividades extracurriculares das instituições escolares públicas e privadas". As instituições que a devem ministrar são: "I - educação básica: educação infantil, ensino fundamental e ensino médio; II - formação técnico-profissional; III - educação superior; IV educação para pessoas portadoras de necessidades especiais; $\mathrm{V}$ - educação de jovens e adultos" (GDF, 2006, p. 2-3).

A lei especifica que: $₫ 1^{\circ}$ - Em cursos de formação superior e especialização técnicoprofissional, devem ser incorporados conteúdos que tratem das interações das atividades profissionais com o meio ambiente natural e social; $\int 2^{\circ}$ - A educação ambiental deverá ser desenvolvida como uma prática educativa integrada, contínua e permanente em todos os níveis e modalidades do ensino formal (GDF, 2006).

Esta lei é a atualmente vigente, e estabelece, entre outros, os objetivos seguintes para a educação ambiental: o desenvolvimento de uma compreensão do meio ambiente nas suas múltiplas e complexas relações; fortalecimento de uma consciência crítica sobre os problemas socioambientais; incentivar a participação comunitária permanente na preservação ambiental; estimular a cooperação entre as regiões administrativas do DF com os municípios do entorno visando uma sociedade com maior sustentabilidade; contribuir para democratizar as informações ambientais; e fomentar e fortalecer a ciência e criação de tecnologias menos poluentes (GDF, 2006).

Entre novembro de 2016 e março de 2017, foi realizada a pesquisa "Mapeamento das Ações de Educação Ambiental do DF", proposta pela Comissão Interinstitucional de Educação Ambiental (Ciea) e desenvolvida em parceria entre a Secretaria de Estado de Meio Ambiente (Sema), a Companhia de Planejamento do Distrito Federal (Codeplan) e a Secretaria de Estado de Educação (Seedf). A pesquisa foi respondida por 143 instituições, das quais foram validadas 122. Destas, $56 \%$ pertencem ao setor público, $31 \%$ são do terceiro setor e $13 \%$ do setor privado. As instituições que participaram da pesquisa estão territorialmente distribuídas desta forma: 25 no Plano Piloto, nove em Taguatinga, seis em Sobradinho e cinco em Brazlandia. (GDF, 2017c).

As áreas de ação prioritária para fortalecer a educação ambiental no DF são sete: "Investimento em Capacitação; Investimento em Infraestrutura; Elaboração e Difusão de Material Didático e de Comunicação; Estabelecimento de Rede de Educadores e Parceiros; Formação de Formadores e Educadores; Apoio e Financiamento às Instituições; e Efetiva Inclusão de EA nas Atividades de Educação" (SEMA, 2017, p. 4). Como pode ser verificado na Tabela 1, as atividades de educação ambiental realizadas em maior número foram as ações/práticas em contato com a natureza, seguido de campanhas educativas, eventos pontuais e datas comemorativas e mobilização socioambiental. As atividades menos realizadas foram produção de materiais didáticos e de comunicação e ações de arte-educação. A Tabela 1 mostra que o terceiro setor realiza mais ações em mobilização 
socioambiental, eventos, campanhas educativas e ações/práticas em contato com a natureza. O setor privado, por sua vez, trabalha mais com campanhas educativas e eventos pontuais, enquanto o setor público privilegia as ações/práticas em contato com a natureza e campanhas educativas. Estas atividades foram, na sua maioria, gratuitas.

\section{Tabela 1 - Atividades de educação ambiental desenvolvidas em 2016}

\begin{tabular}{lccccc}
\hline Atividades de EA & Sim & Não & $\begin{array}{c}\text { Terceiro } \\
\text { Setor \% }\end{array}$ & $\begin{array}{c}\text { Setor } \\
\text { Privado \% }\end{array}$ & $\begin{array}{c}\text { Setor } \\
\text { Público \% }\end{array}$ \\
\hline Mobilização socioambiental & $42(56 \%)$ & $33(44 \%)$ & 70 & 22 & 56 \\
Campanhas Educativas & $47(63 \%)$ & $28(37 \%)$ & 65 & 67 & 60 \\
Formação e Capacitação & $34(45 \%)$ & $41(55 \%)$ & 43 & 44 & 47 \\
Arte Educação Ambiental & $29(39 \%)$ & $46(61 \%)$ & 39 & 33 & 40 \\
Produção Material didáticos & $26(35 \%)$ & $49(65 \%)$ & 35 & 22 & 37 \\
Práticas com a Natureza & $52(69 \%)$ & $23(31 \%)$ & 65 & 33 & 79 \\
Eventos Pontuais & $42(57 \%)$ & $32(43 \%)$ & 70 & 56 & 51 \\
\hline
\end{tabular}

Fonte: Secretaria de Meio Ambiente, Secretaria de Educação, Codeplan, 2016.

O documento sobre o mapeamento das atividades de EA mostra também que 70\% das ações foram realizadas com crianças e adolescentes, o qual é relevante, pois trata-se de conscientização e capacitação das faixas etárias que representam a esperança para conseguir as mudanças e atitudes necessárias da população perante a urgência da preservação do meio ambiente e das próprias condições de vida (GDF, 2017).

\section{Considerações finais}

A urbanização desordenada e sem controle é uma causa determinante da degradação do meio ambiente no Distrito Federal, ocasionando graves impactos na cobertura vegetal de Cerrado, nos recursos hídricos, no aumento dos resíduos sólidos e na perda da qualidade de vida. Esta situação demanda a execução de políticas públicas existentes, orientadas à criação de consciência ambiental e de atitudes proativas da população para preservação do meio ambiente.

O forte impacto global sobre todos os recursos naturais que a urbanização sem controle ocasiona exige que a Lei Complementar N. 948 de 2019, denominada Lei de Uso e Ocupação do Solo do Distrito Federal (Luos), seja implementada com rigor, na medida em que estabelece os critérios e os parâmetros de uso e ocupação do solo para lotes e projeções na macrozona urbana do Distrito Federal. Entretanto, essas diretrizes não estão sendo cumpridas e, ainda, a urbanização necessita de maior 
controle e fiscalização. Outra consequência da urbanização sem ordenamento é o aumento das desigualdades urbanas e das condições deficitárias das moradias e dos serviços básicos de grande parte da população que habita as periferias e assentamentos urbanos em diferentes regiões administrativas do Distrito Federal.

A ocupação de Áreas de Preservação Permanente como nascentes, matas ciliares e zonas de recarga dos rios, além das encostas dos morros, tem ocasionado grave impacto nos recursos hídricos, contribuindo para o desabastecimento e o drástico racionamento de água no DF. Por esta grave degradação dos recursos hídricos e a ameaça real de falta de água na capital federal, é que devem ser procuradas e estabelecidas novas fontes de captação e reforçada a preservação e recuperação das fontes existentes.

Estas iniciativas fazem parte da Lei N. 2.725, que estabeleceu a política de recursos hídricos no DF em 2001, e, desde então, seus objetivos foram prioritariamente assegurar e aumentar a disponibilidade de água, promover a utilização racional deste recurso e prevenir e atuar contra eventos de causas naturais ou sociais que possam ocasionar problemas ao abastecimento da água no DF. Desta forma, cabe às autoridades distritais e às comunidades trabalharem por esses objetivos vigentes.

Os resíduos sólidos continuam tendo um deficiente manejo, principalmente por falta de educação e consciência ambiental de grande parte da população. Não é somente na periferia e nos assentamentos pobres onde há dificuldades com a coleta seletiva e disposição adequada dos resíduos, mas, também, no Plano Piloto e em áreas residenciais de Brasília, ainda se encontra lixo nas ruas e resíduos da construção civil em lugares inadequados. Perante esta situação é necessária uma política de maior de fiscalização e aplicação de ações coercitivas aos poluidores ou infratores, tal como estabelece a Política Nacional de Meio Ambiente de 1981 e a Lei de Crimes Ambientais.

A Lei N. 5.418 de 2014, que faz determinações a respeito dos resíduos sólidos no DF, propõe um manejo integrado para todos, incluindo coleta seletiva, tratamento e disposição final adequada dos resíduos sólidos, bem como uso de tecnologias, o incentivo à reciclagem e erradicação de lixões. Porém, de acordo com a realidade, são necessárias mais ações de educação para a população, dentro do critério que o importante não é ter um excelente sistema de limpeza pública, mas, sim, uma adequada educação ambiental da população para que não deposite ou lance lixo em espaços públicos e/ou inadequados.

Finalmente, cabe assinalar que, não obstante a ampla e particular legislação sobre esses quatro aspectos analisados no DF, a degradação do meio ambiente é preocupante e tem na falta de educação e de consciência ambiental o principal fator determinante deste fenômeno. Neste sentido, é indispensável que se continuem e se ampliem ações para conscientizar a população com atitudes e comportamentos de maior respeito e conservação do meio ambiente. Da mesma forma, continuar com a educação e conscientização de crianças e adolescentes nas escolas, pois se 
sabe que são eles os melhores difusores na sociedade da educação que recebem nas instituições educativas.

\section{Fonte(s) de Financiamento}

FUNADESP-Fundação Nacional de Desenvolvimento do Ensino Superior Particular; UNIALFA-Centro Universitário Alves Faria.

\section{Referências}

ADASA. Níveis dos reservatórios dos sistemas Rio Descoberto e Santa Maria. Brasília/DF: Agência Reguladora de Águas, Energia e Saneamento Básico do Distrito Federal, 2021. Disponível em: https://www.caesb.df.gov.br/nivel-dosreservatorios. Acesso em: 20 fev. 2021.

ADASA. Resolução 20 de novembro de 2016. Brasília/DF: Agência Reguladora de Águas, Energia e Saneamento Básico do Distrito Federal, 2016.

ADASA. Nível dos reservatórios. Brasília/DF: Agência Reguladora de Águas, Energia e Saneamento Básico do Distrito Federal, 2017. Disponível em: http://www.adasa.df.gov.br/images/stories/anexos/mapas/mapa $\% 20$ hidrografic o\%20-\%20a4\%20net.pdf. Acesso em: 15 set. 2020.

AGÊECIA BRASÍLIA. Plano Integrado de enfrentamento a crise hídrica. Brasília, DF, 2017. Disponível em: https://www.agenciabrasilia.df.gov.br/wpconteudo/uploads/2017/03/plano-integrado-de-enfrentamento-a-crise-hidricagoverno-de-brasilia.pdf. Acesso em 12/11/2020.

BRASIL. Lei N. 12.305 de agosto de 2010. Institui a Política Nacional de Resíduos Sólidos (altera a Lei N. 9.605 de 1998 e dá outras providencias). Brasília/DF, 2010.

BRASIL. Lei 3833 de 27 de março de 2006. Dispõe sobre a educação ambiental, institui a política de Educação Ambiental do Distrito Federal e cria o Programa de Educação Ambiental do Distrito Federal. Brasília/DF, 2006. 
BRASIL. Lei N. 10.257 de 2001. Regulamenta os artigos 182 e 183 da Constituição Federal. Brasília/DF, 2001.

BRASIL. Lei N. 9.433 de 8 de janeiro de 1997. Institui a Política Nacional de Recursos Hídricos. Brasília/DF, 1997.

BRASIL. Lei N. 9.795 de 1999. Institui a Política Nacional de Educação Ambiental. Brasília/DF, 1999.

BRASIL. Lei N. 6.938 de 31 de agosto de 1981. Dispõe sobre a Política Nacional do Meio Ambiente, seus fins e mecanismos de formulação e aplicação. Brasília/DF, 1981.

CASTELLS, Manuel. La cuestión urbana. México/DF: Siglo XXI, 1976.

CÂMARA dos deputados. Destinação de resíduos sólidos orgânicos no DF. Brasilia/DF, 2020. https://www.bwexpo.com.br/destinacao-residuos-solidosorganicos-df. Acesso em: 23 jan. 2021.

CODEPLAN. Consumo total anual de água no Distrito Federal, 2016-2019 Brasília/DF: Secretaria de Economia/GDF, 2021.

CODEPLAN. Informalidade territorial e mercado de terras urbanas no Distrito Federal (= Texto para Discussão, 18). Brasília-DF: Secretaria de Economia/GDF, 2016.

CODEPLAN. Sol nascente/pôr do sol: um retrato demográfico e socioeconômico. Brasília/DF: Secretaria de Economia/GDF, 2019.

DELGADO, Guilherme C. Expansão e modernização do setor agropecuário no pós-guerra: um estudo da reflexão agrária. Estudos Avançados, vol. 15, n. 43, p. 157-172, 2001. 
Dye, Thomas D. Understanding Public Policy. Englewood Cliffs, N.J.: Prentice-Hall, 1984.

FERNANDES, Vanira. Impacto do processo de ocupação urbana ao meio ambiente do Distrito Federal. Brasília/DF: Faculdade de Ciências da Saúde / UniCEUB, 2002.

GONZÁLES, Edgar G. Debate conceptual y expectativas nacionales y regionales de la educación ambiental. In: ARRACHE, Martha Viesca. Calidad de vida, medio ambiente y educación en el medio rural. Morelos/México: Centro Regional de Investigaciones Muldisciplinarias/UNAM; El Colegio de Michoacán., 2000 .

GDF. Lei N. 41 de 13 de setembro de 1989. Dispõe sobre a Política Ambiental do Distrito Federal. Brasília/DF: Governo do Distrito Federal, 1989.

GDF. Lei N. 2.725 de 13 de junho de 2001. Institui a política de recursos hídricos e cria o sistema de gerenciamento de recursos hídricos. Brasília/DF: Governo do Distrito Federal, 2001.

GDF. Lei N. 3.833 de 27 de março de 2006. Dispõe sobre a educação ambiental e institui a política de educação ambiental do Distrito Federal. Brasília/DF: Governo do Distrito Federal, 2006.

GDF. Lei N. 5418 de 27 de novembro de 2014. Dispõe sobre a Política Distrital de Resíduos Sólidos. Brasília/DF: Governo do Distrito Federal, 2014.

GDF. Conheça Ceilândia [RA-IX]. Brasília/DF: Governo do Distrito Federal/ Administração Regional de Ceilândia, 2016. Disponível em: http://www.ceilandia.df.gov.br/2016/07/01/conheca-ceilandia-ra-ix-5/ Acesso em: 17 nov. 2020.

GDF. Lei N. 5.803, de 11 de janeiro de 2017. Institui a Política de Regularização de Terras Públicas Rurais pertencentes ao Distrito Federal ou à Agência de Desenvolvimento do Distrito Federal. Brasília/DF: Governo do Distrito Federal, 2017a. 
GDF. Texto Base Conferencia de Meio Ambiente de 2017: cuidando das águas. Brasília/DF: Governo do Distrito Federal, 2017b. Disponível em: http://www.sema.df.gov.br/wp-conteudo/uploads/2017/09/Texto-baseCDMA-2017-Atualizado-2-6-17.pdf. Acesso em: 19 out. 2020.

GDF. Mapeamento das ações de educação ambiental do DF. Brasília/DF: Governo do Distrito Federal/Secretaria de Meio Ambiente/Secretaria de Educação/Codeplan., 2017c.

GDF. Plano Distrital de Gestão Integrada de Resíduos Sólidos. Brasília/DF: Governo do Distrito Federal. 2018.

GDF. Documentos técnicos do Zoneamento Ecológico Econômico. Brasília/DF: Governo do Distrito Federal, 2019a. Disponível em: http://www.zee.df.gov.br/documentos-tecnicos-do-zee-df/. Acesso em: 15 ago. 2020.

GDF. Lei N. 6.269 de 29 de janeiro de 2019. Institui o Zoneamento EcológicoEconômico do Distrito Federal (ZEE-DF). Brasília/DF: Governo do Distrito Federal, 2019b.

GDF. Lei complementar N. 948, de 16 de janeiro de 2019. Aprova a Lei de Uso e Ocupação do Solo do Distrito Federal - LUOS. Brasília/DF: Governo do Distrito Federal, 2019c.

GDF. Revisão da LUOS é Aprovada. Disponível em: https://www.agenciabrasilia.df.gov.br/11/19/2020revisao-da-luos-e-aprovada. Brasília/DF: Governo do Distrito Federal, 2020a.

\section{GDF. Câmara técnica do Conplan discute revisão da Lei de Uso e}

Ocupação do Solo. Brasília/DF: Governo do Distrito Federal, 26 set. 2020b. Disponível em: https://www.agenciabrasilia.df.gov.br/2020/09/26/camaratecnica-do-conplan-discute-revisao-na-lei-de-uso-e-ocupacao-do-solo. Acesso em: 20 jan. 2021. 
GDF. Leis ambientais do Distrito Federal. Brasília/DF: Governo do Distrito Federal/IBRAM/Semarh-DF [data]. Disponível em: http://www.ibram.df.gov.br/leis-ambientais. Acesso em: 23 nov. 2020.

GDF. Sistema integrado de normas jurídicas do DF. Brasília/DF: Governo do Distrito Federal [data]. Disponível em:

http://www.sinj.df.gov.br/sinj/Norma/54488/Lei_3833_27_03_2006.html. Acesso em: 25 jan. 2021.

GOUVÊA, Luiz Alberto de Campos. Brasília: a capital da segregação e do controle social (uma avaliação da ação governamental na área de habitação). São Paulo: Annablume, 1995.

NAKANO, K.; PINTO, J. M. Rio+20 e os desafios da crise urbana. In: MARTINE, George (Org.). População e sustentabilidade na era das mudanças ambientais globais: contribuições para uma agenda brasileira. Belo Horizonte: ABEP; Fund. Carlos Chagas, 2012.

NUNES, Felipe; SERRA, Karina; STEINKE, Valdir. Urbanização e degradação ambiental: análise da ocupação irregular em áreas de proteção permanente na Região Administrativa de Vicente Pires/DF. Revista Brasileira de Geografia Física, Recife, vol. 10, n. 3, p. 722-734, 2017.

PAVIANI, Aldo. “A metrópole terciária”. In: PAVIANI, Aldo (Org.) Brasília: ideologia e realidade (espaço urbano em questão). São Paulo: Projeto, p. 57-79, 1985.

PETERS, B. G. American Public Policy. Chatham, N.J.: Chatham House, 1986.

PORTO ALEGRE. Lei Complementar N. 434/99 (versão janeiro/2007).

Institui o Plano Diretor de Desenvolvimento Urbano Ambiental de Porto Alegre. 2007.

QUIJANO, A. Dependencia, cambio social y urbanización en América Latina. In: SCHTEINGART, M. (Org.) Urbanización y dependencia en América Latina. Buenos Aires: Ediciones SIAP, 1973. 
RUA, Maria; ROMANINI, Roberta. Para aprender políticas públicas [Unidade 5: as abordagens de políticas públicas]. p. 1-35, 2013. Disponível em: https://silo.tips/download/para-aprender-politicas-publicas-7. Acesso em: 09 nov. 2020.

SCHTEINGART, M. (Org.) Urbanización y dependencia en América Latina. Buenos Aires: Ediciones SIAP, 1973.

SECCHI, Leonardo. Políticas públicas: conceitos, esquemas de análise, casos práticos. São Paulo: CENGAGE Learning, 2011.

Secretaria de Meio Ambiente - SEMA, - Secretaria de Educação - Codeplan -Comissão Interinstitucional de Educação Ambiental do Distrito Federal - CIEADF. Mapeamento das ações de Educação Ambiental do DF. Brasília, DF. 2016-2017.

SOARES, Heloisa. Planejamento e ambiente em regiões metropolitanas. In: MARTINE, George (Org.). População e sustentabilidade na era das mudanças ambientais globais: contribuições para uma agenda brasileira. Belo Horizonte: ABEP; Fund. Carlos Chagas, p. 107-122, 2012.

SOUZA, Celina. Políticas públicas: conceitos, tipologias e subáreas. São Paulo: Fund. Luís Eduardo Magalhães, 2002.

WERNECK, Felipe. "Passando a boiada": o segundo ano de desmonte ambiental sob Jair Bolsonaro. Observatório do Clima, 22 jan. 2021. Disponível em: https://www.oc.eco.br/passando-boiada-o-segundo-ano-de-desmonteambiental-sob-jair-bolsonaro. Acesso em: 19 out. 2020. 
Data de submissão: 20/03/2021

Data de aprovação: 14/07/2021

Revisão: Daniela Matthes (português), Anderson de Miranda Gomes (inglês) e Yanet María Reimondo Barrios (espanhol).

\author{
Fernando Negret Fernander. \\ Programa de Pós-Graduação 'Mestrado Profissional' em Desenvolvimento Regional \\ / Faculdades Alves Faria \\ Avenida Mutirão, 2600 \\ 74150-340 Goiânia/GO, Brasil \\ Orcid: http://orcid.org/0000-0002-1253-0725 \\ E-mail: fenegret@uol.com.br \\ Pedro Pietrafesa \\ Mestrado em Desenvolvimento e Planejamento Territorial / Pontifícia Universidade \\ Católica de Goiás \\ Avenida Universitária, 1440 - Setor Universitário \\ 74605-010 Goiânia/GO, Brasil \\ Orcid: http://orcid.org/0000-0003-0542-4753 \\ E-mail: pedro.pietrafesa@gmail.com
}


Fernando Negret Fernandez e Pedro Pietrafesa

248| Revista Brasileira de Desenvolvimento Regional, Blumenau, 9 (3), P.221-248, 2021 